\title{
Ischemic Digital Ulcers Affect Hand Disability and Pain in Systemic Sclerosis
}

\author{
Luc Mouthon, Patrick H. Carpentier, Catherine Lok, Pierre Clerson, Virginie Gressin, \\ Eric Hachulla, Alice Bérezné, Elisabeth Diot, Aurélie Khau Van Kien, Patrick Jego, \\ Christian Agard, Anne Bénédicte Duval-Modeste, Agnès Sparsa, Eve Puzenat, \\ and Marie-Aleth Richard, on behalf of the ECLIPSE Study Investigators
}

\begin{abstract}
Objective. Ischemic digital ulcers (DU) are frequent and severe complications of systemic sclerosis (SSc). The purpose of our study was to assess the effect of DU on hand disability and pain in patients with SSc.

Methods. The Evaluation of the Impact of Recurrent Ischemic DU on Hand Disability in Patients with SSc (ECLIPSE) is a prospective, multicenter, noninterventional study with a 2-year followup. Patients with SSc who experienced at least $1 \mathrm{DU}$ in the previous year and received bosentan therapy were included between October 2009 and March 2011. This cohort is described at the time of inclusion.

Results. There were 190 patients (132 females) from 53 centers. Mean age \pm SD was $43 \pm 15$ years at SSc diagnosis and $53 \pm 15$ years at inclusion. In 105 patients $(56.2 \%)$, DU were the first non-Raynaud symptoms of SSc. The mean time interval between the occurrence of Raynaud phenomenon and the first DU episode was 6.6 \pm 9.1 years. The mean numbers of active DU and fingers affected per patient for both hands were $2.3 \pm 1.8$ and $2.2 \pm 1.6$, respectively. Presence of active DU at inclusion was significantly associated with pain and impaired hand function: Visual Analog Scale for pain (0 to 10) was $6.2 \pm 2.6$ versus $2.5 \pm 2.4(\mathrm{p}<0.0001)$ and Cochin Hand Function Scale for hand disability (0 to 90) was $38 \pm 20$ versus $25 \pm 19$ ( $p<0.0001)$, respectively. Conclusion. DU represent a major sign of SSc, often affecting multiple fingers and both hands. They are significantly associated with pain and hand disability. (First Release June 15 2014; J Rheumatol 2014;41:1317-23; doi:10.3899/jrheum.130900)
\end{abstract}

Key Indexing Terms:

SYSTEMIC SCLEROSIS DIGITAL ULCERS HAND DISABILITY BOSENTAN

From the Université Paris Descartes, Faculté de Médecine, Service de Médecine interne, Centre de référence pour les vascularites nécrosantes et la sclérodermie systémique, Hôpital Cochin, Assistance Publique-Hôpitaux de Paris (APHP), Paris; Service de Médecine vasculaire, $\mathrm{CHU}$ de Grenoble, Grenoble; Service de Dermatologie, Hôpital Sud, CHU Amiens, Amiens; Orgamétrie, Roubaix; Actelion Pharmaceuticals France, Paris; Service de Médecine interne, Centre de référence pour la sclérodermie systémique, Hôpital Claude Huriez, Université Lille 2, Lille; Service de Médecine interne, Hôpital Bretonneau, Tours; Service de Médecine interne, Hôpital Saint Eloi, Montpellier; Service de Médecine interne, Hôpital Sud, Rennes; Service de Médecine Interne, Centre Hospitalier Universitaire Hôtel Dieu, Nantes; Service de Dermatologie, Hôpital Charles Nicolle, Centre Hospitalier Universitaire, Rouen; Service de Dermatologie, Hôpital Dupuytren, CHU Limoges; Hôpital Saint Jacques, Besançon; Service de Dermatologie, Université Aix-Marseille, UMR 911, INSERM CRO2 UMR 911, Centre de recherche en oncologie biologique et oncopharmacologie, Hôpital de la Timone, Assistance Publique Hôpitaux de Marseille, Marseille, France.

Sponsored by Actelion Pharmaceuticals France, which provided funding for logistical support, patient monitoring, project management, data management, statistical analysis, and editorial assistance.

L. Mouthon, MD, PhD, Deputy Chief of Internal Medicine Department, Université Paris Descartes, Faculté de Médecine, Service de Médecine interne, Centre de référence pour les vascularites nécrosantes et la sclérodermie systémique, Hôpital Cochin, APHP; P.H. Carpentier, MD, Chief of Vascular Medicine Department, Service de Médecine vasculaire, CHU de Grenoble; C. Lok, MD, Chief of Dermatology Department,
Service de Dermatologie, Hôpital Sud, CHU Amiens; P. Clerson, MD, Director, Orgamétrie; V. Gressin, MD, Medical Director, Actelion Pharmaceuticals France; E. Hachulla, MD, PhD, Deputy Chief of Internal Medicine Department, Service de Médecine interne, Centre de référence pour la sclérodermie systémique, Hôpital Claude Huriez, Université Lille 2; A. Bérezné, MD, hospital practitioner, Université Paris Descartes, Faculté de Médecine, Service de Médecine interne, Centre de référence pour les vascularites nécrosantes et la sclérodermie systémique, Hôpital Cochin, APHP; E. Diot, MD, hospital practitioner, Service de Médecine interne, Hôpital Bretonneau; A. Khau Van Kien, MD, hospital practitioner, Service de Médecine interne, Hôpital Saint Eloi; P. Jego, MD, Chief of Internal Medicine Department, Service de Médecine interne, Hôpital Sud; C. Agard, MD, PhD, Deputy Chief of Internal Medicine Department, Service de Médecine Interne, Centre Hospitalier Universitaire Hôtel Dieu; A.B. Duval-Modeste, MD, hospital practitioner, Service de Dermatologie, Hôpital Charles Nicolle, Centre Hospitalier Universitaire; A. Sparsa, $M D, P h D$, hospital practitioner, Service de Dermatologie, Hôpital Dupuytren, CHU Limoges; E. Puzenat, MD, hospital practitioner, Hôpital Saint Jacques; M-A. Richard, MD, PhD, Chief of Dermatology Department, Service de Dermatologie, Université Aix-Marseille, UMR 911, INSERM CRO2 UMR 911, Centre de recherche en oncologie biologique et oncopharmacologie, Hôpital de la Timone, Assistance Publique Hôpitaux de Marseille.

Address correspondence to Dr. L. Mouthon, Service de Médecine Interne, Hôpital Cochin, 27 Rue du Faubourg Saint-Jacques, 75679 Paris Cedex 14, France.E-mail: luc.mouthon@cch.aphp.fr Accepted for publication March 12, 2014. Personal non-commercial use only. The Journal of Rheumatology Copyright (C) 2014. All rights reserved. 
Systemic sclerosis (SSc) is a connective tissue disease characterized by vascular damage, fibrosis of skin and internal organs, and production of autoantibodies ${ }^{1}$. Digital vasculopathy, which is responsible for Raynaud phenomenon (RP) and for the occurrence of ischemic digital ulcers (DU), is a hallmark of $\mathrm{SSc}^{2}$. Thus, a history of DU is reported in 44-60\% of patients with $\mathrm{SSc}^{3,4,5,6,7}$ and DU have been associated with severe pain, disability, and impaired quality of life $(\mathrm{QoL})^{3,6,8}$.

In patients with $\mathrm{SSc}$, hand function can be evaluated using the Cochin Hand Function Scale (CHFS), a self-assessment questionnaire that has been set up for patients with rheumatoid arthritis ${ }^{9}$ and validated in patients with $\mathrm{SSc}^{10,11}$. We recently reported that SSc patients with active (i.e., unhealed) DU have reduced wrist and hand mobility, increased global and hand disabilities, and altered health-related QoL compared to those without active $\mathrm{DU}^{8}$.

Patient education is key in DU prevention, with recommendation for reducing cold exposure, avoiding use of tobacco and vasoconstrictive agents, and preventing hand injury and repeated microtrauma. Treatment options for SSc-related digital vasculopathy are based on aggressive vasodilation, with the objective to improve blood flow to ischemic areas. These options include longterm treatment with calcium channel blockers to reduce the frequency and/or severity of RP attacks, intravenous prostanoids to treat severe RP and active DU, and the dual endothelin receptor antagonist bosentan to prevent the occurrence of DU in patients with ongoing DU disease ${ }^{12}$. Indeed, in patients with SSc, the preventive effect of bosentan on the occurrence of new DU was demonstrated in 2 prospective randomized studies ${ }^{13,14}$. Sildenafil, a phosphodiesterase type 5 inhibitor, reduces RP, and according to pilot studies ${ }^{15}$, may be effective in promoting healing of DU.

To assess the effect of recurrent ischemic DU on hand disability in patients with SSc, we have set up a prospective, multicenter, longitudinal, noninterventional study in patients with ongoing ischemic DU disease. To focus on a homogeneous study population, ongoing ischemic DU disease was defined as a recent history of DU ( $\geq 1$ ischemic DU during the preceding year) and patients had to be eligible for bosentan therapy. We herein present the patients' characteristics at the time of inclusion and assess the effect of the presence of active ischemic DU on hand functionality, pain, and QoL.

\section{MATERIALS AND METHODS}

Study design. ECLIPSE (Evaluation of the Impact of Recurrent Ischemic DU on Hand Disability in Patients with SSc) is a prospective, longitudinal, noninterventional, multicenter study with a 2-year followup (primary endpoint at 1 year; AC-052-517). A total of 201 patients were planned to be recruited in 70 French centers from October 2009 to March 2011. Few categories of physicians are allowed to prescribe bosentan in France and study investigators were restricted to hospital-based internal and vascular medicine specialists, dermatologists, and rheumatologists.
Patients. The study enrolled patients aged $\geq 18$ years, with limited cutaneous (lcSSc) or diffuse cutaneous SSc (dcSSc) according to American College of Rheumatology ${ }^{16}$ or Leroy and Medsger ${ }^{17}$ criteria. Eligible patients had to have experienced $\geq 1$ predominantly ischemic DU during the previous year, regardless of whether they presented active DU at inclusion. A predominantly ischemic DU was defined as an ulcer located on the pulpar face of the fingers, distal to the proximal interphalangeal joints, and not facing a calcinosis or bone profile (otherwise they were considered mechanical DU) ${ }^{13}$. All DU described herein refer to "predominantly ischemic DU" unless otherwise specified. Moreover, patients should be eligible for bosentan therapy according to the approved indication by the European Medicines Agency ${ }^{18}$.

Variables of assessment at inclusion. The following SSc/DU disease characteristics were collected from the patient's history: disease form (lcSSc or dcSSc); modified Rodnan Skin Score ${ }^{19}$; history of ischemic ulcerative disease; characteristics of current DU, if any (ischemic as well as nonischemic); number of previous DU episodes (a DU episode being defined as a time period when at least 1 active DU is present); sequelae resulting from DU history; and presence of other complications of SSc (esophageal, gastrointestinal, hand joint and muscle involvement; left ventricular involvement; interstitial lung disease; pulmonary arterial hypertension; and renal crisis). Clinical examination looked for potential mechanical causes of hand disability such as ankylosis of the distal and proximal interphalangeal joints, of the metacarpophalangeal (MCP) joints, presence of a nonulcerative calcinosis, tendinous retractions in the fingers, presence of a mechanical DU, loss of substance, autoamputation, surgical amputation, arthrodesis, and sympathectomy. Factors likely to influence the severity of digital vasculopathy were collected, such as smoking status, exposure to cold, and intake of vasoconstrictive agents. Immunological data recorded anticentromere and antitopoisomerase I (Scl-70) antibodies at enrollment. Systemic therapies prescribed for treatment of DU and/or SSc in addition to bosentan were collected, with special focus on calcium channel blockers. Finally, uses of supportive measures (such as physiotherapy, orthesis) were also collected.

Global disability was assessed with the self-administered Health Assessment Questionnaire-Disability Index (HAQ-DI) ${ }^{19}$, the scale ranging from 0 (no disability) to 3 (maximal disability). The HAQ-DI comprises 20 items divided into 8 domains and has been validated in French ${ }^{20}$.

Hand disability was evaluated by use of the self-administered CHFS ${ }^{9}$, with 18 items concerning daily activities, each question scored on a scale of 0 (performed without difficulty) to 5 (impossible to do). The total score is obtained by adding the scores of all items (range 0-90). This questionnaire has been validated in French in patients with $\mathrm{SSc}^{10,11}$

The French version of the Medical Outcomes Study Short Form-36 health survey (SF-36) was used to assess QoL $^{21}$. This self-administered questionnaire covers 8 areas: Physical Function, Physical Role, Bodily Pain, General Health, Vitality, Social Functions, Emotional Role, and Mental Health. For each area, the score ranges from 0 (poorest) to 100 (best). Scores can also be summarized in 2 global scores: the Physical Component Summary (PCS) and Mental Component Summary (MCS $)^{22}$. Pain was rated by patients on a 10-point visual analog scale (VAS).

Ethical considerations. Our study was conducted in compliance with the Good Clinical Practices protocol and Declaration of Helsinki principles. According to French law, formal approval from an ethics committee is not required for observational studies. Patients gave their oral consent to participate.

Statistical analysis. For the cross-sectional analysis of the ECLIPSE cohort at the time of inclusion, presented here, descriptive statistics were used to summarize patient data and disease characteristics. Only the SF-36 physical and mental components were normally distributed. Two sample t-tests were performed to compare outcome variables between different patient groups. To identify potential confounding factors influencing the CHFS in addition to the presence of active DU, univariate regression analyses were performed including the following variables: presence of nonulcerative calcinosis, tendinous retractions, ankylosis of the distal and proximal inter- 
phalangeal joints, ankylosis of the MCP joints, DU located on the dorsal surface of the fingers, DU complicating calcinosis, DU located on bone profile, loss of substance, autoamputation, surgical amputation, arthrodesis, and sympathectomy. A multivariate regression analysis was then conducted to identify independent risk factors for increased CHFS.

\section{RESULTS}

Between October 2009 and March 2011, 194 patients were recruited at 53 centers. The number of patients enrolled by internists, dermatologists, vascular medicine specialists and rheumatologists was 92, 65, 26, and 11, respectively. More patients were recruited during January-March (75) and October-December (85) than during April-June (16) and July-September (14).

Four patients had no history of hand DU within the preceding year and were excluded from the analysis. Thus, 190 patients could be analyzed. Demographics, clinical characteristics, immunological data, and the history of DU are shown in Tables 1 and 2. The population included a majority of middle-aged female patients with an almost balanced distribution of $\mathrm{lcSSc}$ and dcSSc, with frequent gastrointestinal and pulmonary complications. Duration of the DU was $7.6 \pm 8.2$ years. In our cohort, the time from first RP to DU tended to be shorter in patients with dcSSc compared to those with lcSSc $(5.7 \pm 8.3$ vs $7.3 \pm 9.6$ yrs, $\mathrm{p}=0.24)$.

History of $D U$ in the overall population. DU was the first non-RP manifestation in 105 patients (56.2\%; Table 2). One hundred eight patients $(56.8 \%)$ had over 5 DU episodes since their first DU. Many patients had sequelae from previous DU including loss of substance (63.2\%), autoamputation (6.8\%), and/or surgical amputation (10.0\%). Up to $15.3 \%$ patients had an aggravating factor, including smoking, cold exposure, and/or vasoconstrictive drug treatment. A limited number of patients were currently receiving adjunctive therapy such as physiotherapy (14.7\%) or orthoses $(10.0 \%)$. Patients may have received calcium channel blockers $(60.9 \%, \mathrm{n}=69)$ or intermittent iloprost (18.5\%) for the treatment of SSc and/or DU in addition to bosentan $(100 \%)$.

Number of $D U$, and hands and fingers affected in patients with active DU at inclusion. The number of active DU per patient, per hand, and per finger is depicted in Figure 1. At inclusion, 113 patients $(59.5 \%)$ had 1 or more active DU (Table 3), with a mean total number of DU of $2.3 \pm 1.8$ (median 2). The dominant hand of 88 patients (77.9\%) was affected and $43(38.1 \%)$ presented with DU on both hands. The mean number of DU on the right and left hands was 1.4 \pm 1.1 and $0.9 \pm 1.1$, respectively. Similar numbers were found for the mean number of DU affecting the dominant $(1.4 \pm 1.2)$ and nondominant hand $(1.0 \pm 1.1)$. The mean number of fingers affected by DU per patient overall, of the right and left hand, respectively, amounted to $2.2 \pm 1.6$ (median 2), $1.3 \pm 1.0$ (median 1), and $0.9 \pm 1.0$ (median 1 ). Whatever the hand involved, the second (index) and third (middle) finger were most often affected (Figure 1).
Table 1. Demographics and clinical characteristics at inclusion in 190 patients with SSc. All values are n (\%) unless otherwise specified.

Patient Characteristics

\begin{tabular}{|c|c|}
\hline \multicolumn{2}{|l|}{ Demographics } \\
\hline No. patients & $190(100)$ \\
\hline Female & $132(69.5)$ \\
\hline Age at inclusion, yrs, mean \pm SD & $53 \pm 15$ \\
\hline \multicolumn{2}{|l|}{ Clinical characteristics } \\
\hline $\begin{array}{l}\text { Age at diagnosis of SSc, mean } \pm \text { SD yrs } \\
\text { Disease form }\end{array}$ & $43 \pm 15$ \\
\hline Limited SSc & 109 (57.4) \\
\hline Diffuse SSc & $81(42.6)$ \\
\hline $\begin{array}{l}\text { Time since RP occurrence, yrs, } \\
\text { mean } \pm \mathrm{SD}(\mathrm{IQR})\end{array}$ & $14 \pm 12(5-20)$ \\
\hline $\begin{array}{l}\text { Time since first non-RP symptom, yrs, } \\
\text { mean } \pm \text { SD (IQR) }\end{array}$ & $9.7 \pm 8.4(3-14)$ \\
\hline \multicolumn{2}{|l|}{ Organ involvement } \\
\hline Any organ involvement & $160(84.2)$ \\
\hline Pulmonary fibrosis & $86(45.3)$ \\
\hline Pulmonary arterial hypertension* & $22(11.6)$ \\
\hline History of renal crisis & $6(3.2)$ \\
\hline Esophagus involvement & $140(73.7)$ \\
\hline Gastrointestinal involvement & $52(27.4)$ \\
\hline \multicolumn{2}{|l|}{ Skin involvement } \\
\hline Modified Rodnan Skin Score, mean \pm SD & $14.2 \pm 8.8$ \\
\hline$\leq 14$ & $108(56.8)$ \\
\hline$>14$ & $81(42.6)$ \\
\hline Score not available & $1(0.5)$ \\
\hline \multicolumn{2}{|l|}{ Factors limiting hand function } \\
\hline Nonulcerative calcinosis & $27(14.2)$ \\
\hline Tendinous retractions & $81(42.6)$ \\
\hline Ankylosis of the distal interphalangeal joints & $128(67.4)$ \\
\hline Ankylosis of the proximal interphalangeal joints & $107(56.3)$ \\
\hline Ankylosis of the metacarpophalangeal joints & $61(32.1)$ \\
\hline \multicolumn{2}{|l|}{ Immunological characteristics } \\
\hline Antitopoisomerase 1 (Scl-70) antibodies & $97 / 188(51.6)$ \\
\hline Anticentromere antibodies & $54 / 181(29.8)$ \\
\hline \multicolumn{2}{|l|}{ Treatment for DU } \\
\hline Bosentan & $190 / 190(100)$ \\
\hline Calcium channel blockers & $42 / 69(60.9)$ \\
\hline Iloprost & $35 / 190(18.4)$ \\
\hline
\end{tabular}

*Determined by either right heart catheterization with a mean pulmonary pressure $>25 \mathrm{~mm} \mathrm{Hg}$ or Doppler echocardiography. DU: digital ulcer; IQR: interquartile range; RP: Raynaud phenomenon; SSc: systemic sclerosis.

In 23 patients (20.4\% of patients with active DU), the DU diameter was $\geq 1 \mathrm{~cm}$.

Of the 113 patients with active DU, 28 (24.8\%) also presented with nonischemic DU in addition to ischemic DU at inclusion (Table 3). Complications included osteitis (1.8\%), cutaneous infection (9.7\%), and gangrene (4.4\%).

Hand disability, pain, and QoL according to presence of ischemic active DU at inclusion. Outcome measure scores at inclusion for the total population, for patients with and without active DU at entry, are displayed in Table 4. The Global Disability Index of the HAQ was not different in patients with and without active DU at baseline. Conversely, the mean baseline scores of the CHFS and VAS were $38 \pm$ 20 and $6.2 \pm 2.6$ in patients with active DU versus $25 \pm 19$ 
Table 2. History of digital ulcers (DU) at inclusion and sequelae from previous DU in 190 patients with SSc. All values are number of patients, shown as $\mathrm{n}(\%)$, except as otherwise specified.

History and Sequelae of DU

\begin{tabular}{lc}
\hline Occurrence of DU & \\
DU first sign other than RP & $105(56.2)$ \\
$>5$ DU episodes* since first DU & $108 / 188(57.4)$ \\
DU episodes* during last year, mean \pm SD (median) & $1.95 \pm 2.0(1)$ \\
Time intervals, yrs, mean \pm SD (IQR) & \\
RP-first DU, $\mathrm{n}=187$ & $6.6 \pm 9.1(1-9)$ \\
RP-first DU in patients with limited SSc, $\mathrm{n}=108$ & $7.3 \pm 9.6(0-7)$ \\
RP-first DU in patients with diffuse SSc, $\mathrm{n}=79$ & $5.7 \pm 8.3(1-10)$ \\
First non-RP sign-first DU, $\mathrm{n}=187$ & $2.2 \pm 4.5(0-2)$ \\
First DU-study enrollment, $\mathrm{n}=187$ & $7.6 \pm 8.2(2-10)$ \\
Sequelae from previous DU** & \\
Loss of substance & $120(63.2) / 106$ \\
Autoamputation & $13(6.8) / 12$ \\
Surgical amputation & $19(10) / 13$ \\
Arthrodesis & $6(3.2) / 3$ \\
Sympathectomy & $3(1.6) / 3$ \\
Aggravating factors & \\
Current smoking & $29(15.3)$ \\
Cold exposure & $22(11.6)$ \\
Vasoconstrictive treatment & $5(2.6)$
\end{tabular}

*A DU episode is defined as a time period when at least 1 active DU is present. ** On at least 1 hand/on dominant hand. IQR: interquartile range; DU: digital ulcer; RP: Raynaud phenomenon; SSc: systemic sclerosis.
Table 3. Characteristics of digital ulcers (DU) in 113 patients with at least 1 active ischemic DU at inclusion. All values are no. patients (\%).

Characteristics of DU

\section{No. DU}

Patients having at least $1 \mathrm{DU}$

$113(100)$

$\geq 2$ DU

64 (56.6)

$\geq 4 \mathrm{DU}$

$18(15.9)$

Pathogenesis of DU

Ischemic DU

$113(100)$

At least 1 other concomitant DU on the dorsal surface of the fingers

At least 1 other concomitant DU complicating calcinosis

At least 1 other concomitant DU on bone profile

At least 1 other concomitant DU related to nonischemic mechanism

$15(13.3)$

Sequelae of previous DU

Loss of substance

Autoamputation

Surgical amputation

$69(61.1)$

$7(6.2)$

$13(11.5)$

Arthrodesis

$3(2.7)$

Sympathectomy

$5(4.4)$

Complications of active DU at inclusion

Osteitis

Cutaneous infection

\section{Mean number of DU per patient}

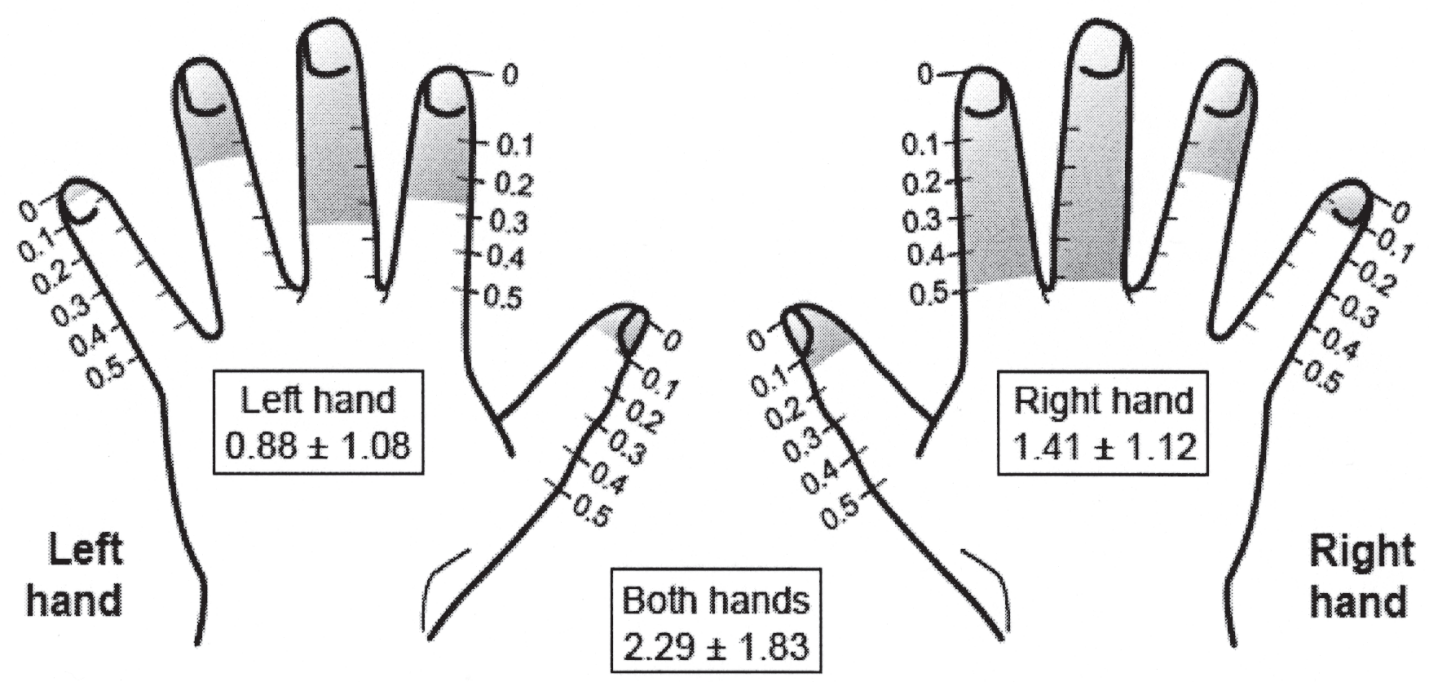

Figure 1. Digital ulcers (DU) in patients with DU at inclusion. Data are presented for 113 patients with at least 1 active DU at inclusion. Shaded areas represent the mean number of DU per finger of each hand; numbers of DU per finger, per hand, and total number of DU are mean $\pm \mathrm{SD}$. 


\begin{tabular}{|c|c|c|c|c|}
\hline & Whole Group, $\mathrm{n}=190$ & With DU at Entry, $\mathrm{n}=113$ & Without DU at Entry, n = 77 & $\mathrm{p}$ \\
\hline HAQ-DI, range $0-3$ & $1.0 \pm 0.7, \mathrm{n}=189$ & $1.1 \pm 0.7, \mathrm{n}=113$ & $0.9 \pm 0.7, \mathrm{n}=76$ & 0.15 \\
\hline CHFS, range 0-90 & $32 \pm 21, \mathrm{n}=174$ & $38 \pm 20, n=99$ & $25 \pm 19, \mathrm{n}=75$ & $<0.0001$ \\
\hline VAS, range $0-10$ & $4.6 \pm 3.1, n=178$ & $6.2 \pm 2.6, n=104$ & $2.5 \pm 2.4, \mathrm{n}=74$ & $<0.0001$ \\
\hline SF-36 PCS & $38 \pm 9, \mathrm{n}=182$ & $37 \pm 9, n=110$ & $39 \pm 9, n=72$ & 0.29 \\
\hline Physical Functioning & $53 \pm 28$ & $52 \pm 29$ & $54 \pm 27$ & 0.63 \\
\hline Role-Physical & $47 \pm 29$ & $45 \pm 28$ & $49 \pm 31$ & 0.37 \\
\hline Bodily Pain & $43 \pm 24$ & $39 \pm 22$ & $48 \pm 25$ & 0.01 \\
\hline General Health & $39 \pm 20$ & $38 \pm 20$ & $42 \pm 19$ & 0.19 \\
\hline SF-36 MCS & $38 \pm 12, \mathrm{n}=182$ & $37 \pm 12, \mathrm{n}=110$ & $40 \pm 11, n=72$ & 0.12 \\
\hline Vitality & $39 \pm 19$ & $38 \pm 20$ & $40 \pm 18$ & 0.46 \\
\hline Social Functioning & $58 \pm 27$ & $56 \pm 27$ & $62 \pm 26$ & 0.11 \\
\hline Role-Emotional & $56 \pm 30$ & $54 \pm 30$ & $59 \pm 30$ & 0.24 \\
\hline Mental Health & $51 \pm 21$ & $48 \pm 22$ & $55 \pm 19$ & 0.04 \\
\hline
\end{tabular}

CHFS: Cochin Hand Function Scale; DU: digital ulcer; HAQ-DI: Health Assessment Questionnaire-Disability Index; MCS: Mental Component Summary; PCS: Physical Component Summary; SF-36: Medical Outcomes Study Short Form-36 health survey; SSc: systemic sclerosis; VAS: visual analog scale.

and $2.5 \pm 2.4$ in patients without active DU, respectively ( $\mathrm{p}<0.0001)$. Only 5 patients without DU $(6.7 \%)$ showed a CHFS score over 50, compared with 29 patients with DU (29.3\%). Similarly, 10 patients without DU (13.5\%) showed a VAS score over 5, compared with 63 patients with DU (60.6\%; Figure 2). Patients with active DU at inclusion had a significantly poorer QoL than patients without active DU with regard to the Bodily Pain and the Mental Health subscale of the SF-36.

Confounding factors on hand function. Results from univariate regression analyses are presented in Table 5. In multivariate analysis, only presence of active DU was associated with hand function limitation measured by increased CHFS ( $\mathrm{p}<0.0001)$. The CHFS was linearly correlated with the number of DU (on both hands, on right and left hand, on dominant and nondominant hand) in the overall

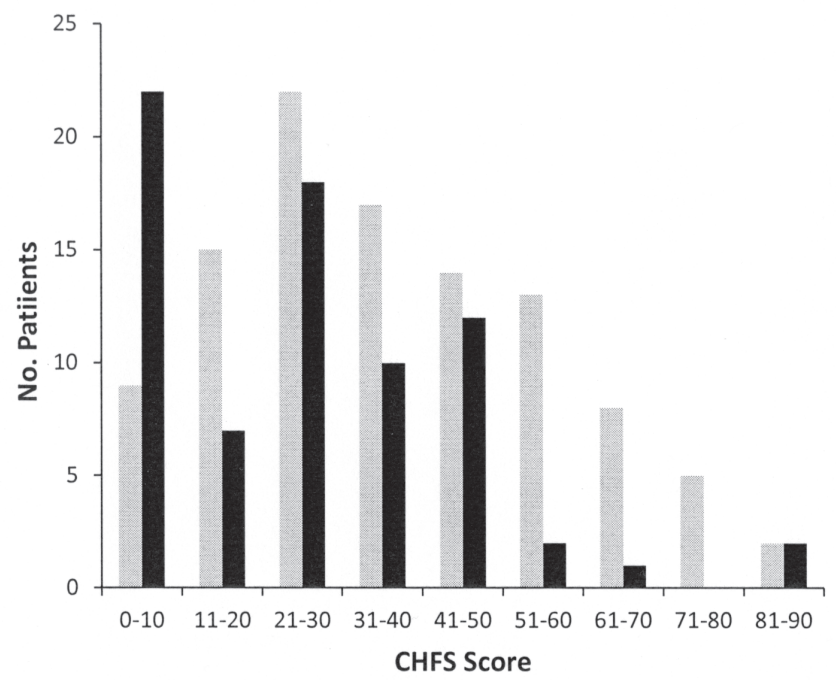

population $(\mathrm{p}=0.0002, \mathrm{p}=0.0004, \mathrm{p}=0.003, \mathrm{p}=0.0009$, and $\mathrm{p}=0.002$, respectively), but significance was lost in the group of patients with at least $1 \mathrm{DU}$ at inclusion, suggesting that hand function is altered as soon as $1 \mathrm{DU}$ is present.

\section{DISCUSSION}

We describe the history and extent of DU at the time of inclusion in a large cohort of 190 French patients with SSc and ongoing DU disease, and analyze consequences for hand disability, pain, and QoL. To the best of our knowledge, this is the first prospective nationwide multicenter and multidisciplinary prospective study specifically dedicated to evaluate the functional effect of SSc-related DU.

Our study indicates that DU are a frequent complication of SSc that often present with multiple recurrences and leave sequelae such as loss of substance. Often, multiple

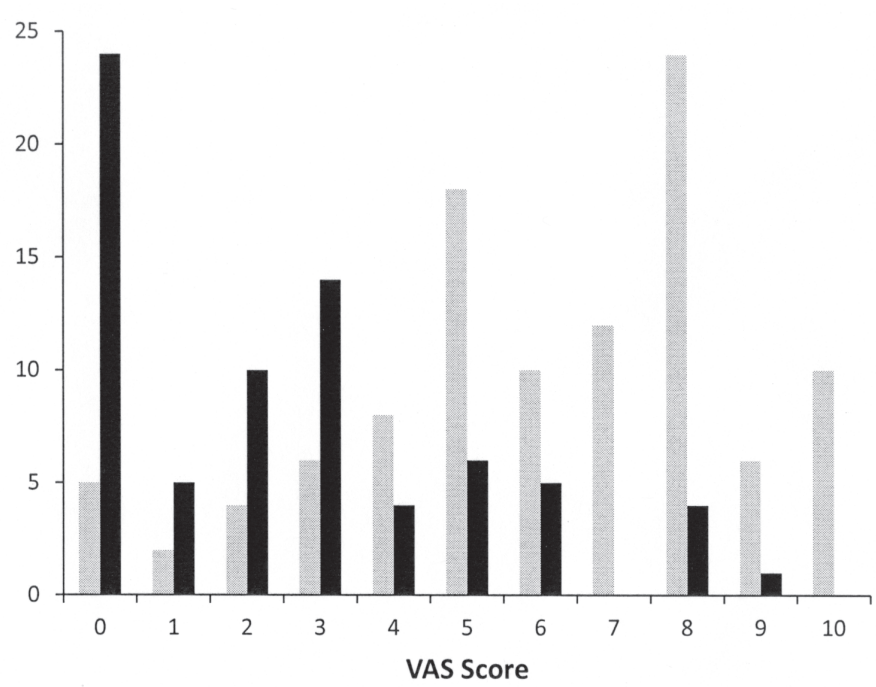

Figure 2. Effect of digital ulcers (DU) on the Cochin Hand Function Scale (CHFS) score (left panel) and on the visual analog scale (VAS) for pain score (right panel). Black bars depict patients without active DU at inclusion $(n=75 / 77$ in left panel; $n=74 / 77$ in right panel); grey bars depict patients with at least 1 active DU at inclusion ( $n=99 / 113$ in left panel; $n=104 / 113$ in right panel). 
Table 5. Effect of mechanical factors limiting hand function on the CHFS - results from univariate regression analyses.

\begin{tabular}{lc}
\hline Mechanical Factors Limiting Hand Function & $\mathrm{p}$ \\
\hline Tendinous retractions & 0.02 \\
Ankylosis of the distal interphalangeal joints & 0.002 \\
Ankylosis of the proximal interphalangeal joints & $<0.0001$ \\
Ankylosis of the metacarpophalangeal joints & 0.0008 \\
DU located on bone profile & 0.02 \\
Autoamputation & 0.04 \\
Surgical amputation & 0.09 \\
Arthrodesis & 0.03 \\
\hline
\end{tabular}

CHFS: Cochin Hand Function Scale; DU: digital ulcers.

concomitant DU affect several fingers of the dominant hand, and both hands in one-third of cases. Patients with active DU present with significant impairment of hand function, increased pain, and altered QoL. Among the multifactorial complications of SSc that may affect hand function, DU play a major role.

In our study, the mean number of DU on the right and left hand was 1.4 and 0.9 , respectively (same findings for the dominant and the nondominant hand, respectively). This is somewhat different from published studies, where the distribution of DU was roughly equal for both hands ${ }^{3}$. The observation that the time from first RP to DU tended to be shorter in patients with dcSSc compared to those with $1 \mathrm{cSSc}$ confirms a recent finding from the European Digital Ulcer Outcomes registry, where DU developed significantly earlier in patients with dcSSc than in those with $\mathrm{lcSSc}^{23}$.

Our present study confirms in a multicenter setting the previous findings that DU severely affect hand function and $\mathrm{QoL}^{3,4,5,6,7}$. In a series of 213 patients with $\mathrm{SSc}$ that we enrolled between 2004 and 2007, 31.4\% of the patients had at least $1 \mathrm{DU}$ at the time of evaluation. These patients with at least $1 \mathrm{DU}$ had a significantly greater HAQ-DI (1.21 \pm 0.72 and $0.93 \pm 0.71, p=0.008$, were reported) and CHFS $(27.4 \pm 20.7$ vs $16.7 \pm 18.2, \mathrm{p}<0.0001)$ than did patients without DU. In addition, hand and wrist mobility as well as the mental score of the SF-36 were significantly diminished $^{8}$. In a second series of 189 patients with SSc whom we enrolled between 2008 and 2009, 59.8\% of patients had a history of DU and $31.7 \%$ had at least $1 \mathrm{DU}$ at the time of evaluation (20\% of whom were taking bosentan). Global disability (HAQ-DI: $1.12 \pm 0.79$ vs $1.39 \pm 0.84, \mathrm{p}=0.001$ ), hand disability (CHFS: $20.2 \pm 18.3$ vs $27.8 \pm 19.1$, p < 0.0001 ), and anxiety (Hospital Anxiety and Depression Scale: $9.9 \pm 5$ vs $8.5 \pm 4.2, \mathrm{p}=0.04$ ) were significantly higher in patients with DU than in patients without $\mathrm{DU}^{6}$. However, it is difficult to compare our data with these 2 studies, which did not require a history of previous DU or treatment with bosentan. Further, only the second study categorized DU according to the possible underlying mechanism (ischemic, mechanical, associated with calcinosis).
The ECLIPSE population described here has a more severe form of digital vasculopathy than the previous populations because it was selected based on a recent history of DU and eligibility for bosentan therapy.

In our study, the mean CHFS was $38 \pm 20$ in patients with active DU versus $25 \pm 19$ in patients without active DU, which is also much higher than in the previous studies, reflecting moderate hand disability around 25 and severe hand disability over $35^{6,8}$. This finding suggests that the more severe the vasculopathy, the more impaired the hand function. Indeed, the effect of active DU on hand function remained statistically significant even when the comparison was adjusted on potentially confounding factors.

Hand disability in patients with SSc involves the skin, subcutaneous tissues, and the microvascular, musculoskeletal, and peripheral nervous systems ${ }^{24}$. These modifications lead to hand deformities and pain and are responsible for the altered hand function. In particular, synovitis, joint contractures, and tendon friction rubs, which appear to be more prevalent in the diffuse form of $\mathrm{SSc}^{25}$, contribute to hand disability in patients with $\mathrm{SSc}^{24}$. Thus, a study observed that arthralgia was more frequent in patients with DU than without DU $(75.0 \% \text { vs } 58.1 \%, \mathrm{p}=0.02)^{6}$. However, in our present study, the results of a multivariate analysis suggest that the greater impairment of hand function in patients with active DU at inclusion is strongly related to the presence of DU and is unlikely to be due to confounding factors. Further, hand function appears to be altered as soon as $1 \mathrm{DU}$ is present.

Our study provides information of major importance in this population of patients with severe ulcerative disease: $15.3 \%$ of the patients had an aggravating factor, including smoking, cold exposure, and/or vasoconstrictive drug treatment, and only $60.9 \%$ of the 69 patients with available data received calcium channel blockers. These findings are relevant for the improvement of clinical practice and patient education.

The strength of our study is that DU description was based on the presence of an active DU at the time of inclusion, with concomitant measure of QoL and hand function. In addition, confounding factors have been taken into consideration when assessing the potential effect of DU on hand function. However, there are a number of limitations to the interpretation of the baseline results in our study: the ECLIPSE population is not representative of the whole SSc population because it is restricted to patients with an ongoing DU disease who were eligible for bosentan, and who were seen in a hospital setting.

We describe initial data from a large contemporary cohort of patients with SSc and ongoing DU disease being treated with bosentan. In our cohort, DU represent a recurrent complication of SSc and are significantly associated with pain and hand disability. Prospective followup at 2 years will provide important information on how recurrent DU episodes influence hand disability. 


\section{ACKNOWLEDGMENT}

The authors thank the patients who kindly participated in this study and the investigators who have contributed to the conduct of this study. Medical writing assistance was provided by Don Dreher (Totzke \& Dreher Scientific Ltd., Geneva, Switzerland) for the first draft and Sylvie Ertel for further writing assistance funded by Actelion Pharmaceuticals Ltd.

\section{APPENDIX}

List of study collaborators: the ECLIPSE Investigators Group: Lok C, Thuillier D, Amiens; Le Clec'h C, Angers; Duchêne F, Belfort; Puzenat E, Besancon; Prey S, Solanilla A, Bordeaux; Bourgault-Villada I, Boulogne Billancourt; Le Hello C, Bienvenu B, Caen; Berthier S, Muller G, Dijon; Remond B, Evreux; Carpentier P, Grenoble; Damade R, Le Coudray; Beneton-Benhard N, Maillard H, Le Mans; Barcat D, Libourne; Hachulla E, Hatron PY, Lille; Sparsa A, Doffoel-Hantz V, Fauchais AL, Limoges; Geffray L, Lisieux; Coppéré B, Jullien D, Lyon; Granier F, Mantes-la-Jolie; Harle JR, Granel B, Richard MA, Marseille; Maurier F, Metz; Cohen JD, Khau Van Kien A, Montpellier; Granel-Brocard F, Nancy; Agard C, Nantes; Queyrel V, Nice; Corondan A, Orléans; Bérezné A, Mouthon L, Crickx B, Picard Dahan C, Eguia B, Francès C, Emmerich J, Fiessinger JN, Mathian A, Lazareth I, Michon-Pasturel U, Paris; Viallard JF, Pessac; Wierzbicka-Hainaut E: Poitiers; Fleuret C, Quimper; Léonard-Lefèbvre F, Reguiai Z, Reims; Jego P, Perdriger A, Rennes; Modeste Duval AB, Rouen; Bonnin A, Royan; Chatelus E, Poindron V, Strasbourg; Diot E, Tours; Bica-Chicinas D, Roger M, Troyes; Wahl D, Zuily S, Vandoeuvre-les-Nancy.

\section{REFERENCES}

1. Mouthon L, Allanore Y, Cabane J, Hachulla E. Sclérodermie systémique. Guillevin L, Meyer O, Sibilia J, eds. Paris: Flammarion Médecine-Sciences; 2012.

2. Galluccio F, Matucci-Cerinic M. Two faces of the same coin: Raynaud phenomenon and digital ulcers in systemic sclerosis. Autoimmun Rev 2011;10:241-3.

3. Hachulla E, Clerson P, Launay D, Lambert M, Morell-Dubois S, Queyrel V, et al. Natural history of ischemic digital ulcers in systemic sclerosis: single-center retrospective longitudinal study. J Rheumatol 2007;34:2423-30.

4. Tiev KP, Diot E, Clerson P, Dupuis-Simeon F, Hachulla E, Hatron $\mathrm{PY}$, et al. Clinical features of scleroderma patients with or without prior or current ischemic digital ulcers: post-hoc analysis of a nationwide multicenter cohort (ItinerAIR-Sclerodermie). J Rheumatol 2009;36:1470-6.

5. Steen V, Denton CP, Pope JE, Matucci-Cerinic M. Digital ulcers: overt vascular disease in systemic sclerosis. Rheumatology 2009;48 Suppl 3:iii19-24.

6. Berezne A, Seror R, Morell-Dubois S, de Menthon M, Fois E, Dzeing-Ella A, et al. Impact of systemic sclerosis on occupational and professional activity with attention to patients with digital ulcers. Arthritis Care Res 2011;63:277-85.

7. Khimdas S, Harding S, Bonner A, Zummer B, Baron M, Pope J, et al. Associations with digital ulcers in a large cohort of systemic sclerosis: results from the Canadian Scleroderma Research Group registry. Arthritis Care Res 2011;63:142-9.

8. Mouthon L, Mestre-Stanislas C, Berezne A, Rannou F, Guilpain P, Revel M, et al. Impact of digital ulcers on disability and health-related quality of life in systemic sclerosis. Ann Rheum Dis 2010;69:214-7.

9. Duruoz MT, Poiraudeau S, Fermanian J, Menkes CJ, Amor B, Dougados M, et al. Development and validation of a rheumatoid hand functional disability scale that assesses functional handicap. J Rheumatol 1996;23:1167-72.

10. Brower LM, Poole JL. Reliability and validity of the Duruoz Hand Index in persons with systemic sclerosis (scleroderma). Arthritis Rheum 2004;51:805-9.
11. Rannou F, Poiraudeau S, Berezne A, Baubet T, Le-Guern V, Cabane $\mathrm{J}$, et al. Assessing disability and quality of life in systemic sclerosis: construct validities of the Cochin Hand Function Scale, Health Assessment Questionnaire (HAQ), Systemic Sclerosis HAQ, and Medical Outcomes Study 36-Item Short Form Health Survey. Arthritis Rheum 2007;57:94-102.

12. Kowal-Bielecka O, Landewe R, Avouac J, Chwiesko S, Miniati I, Czirjak L, et al. EULAR recommendations for the treatment of systemic sclerosis: a report from the EULAR Scleroderma Trials and Research group (EUSTAR). Ann Rheum Dis 2009;68:620-8.

13. Korn JH, Mayes M, Matucci Cerinic M, Rainisio M, Pope J, Hachulla E, et al. Digital ulcers in systemic sclerosis: prevention by treatment with bosentan, an oral endothelin receptor antagonist. Arthritis Rheum 2004;50:3985-93.

14. Matucci-Cerinic M, Denton CP, Furst DE, Mayes MD, Hsu VM, Carpentier P, et al. Bosentan treatment of digital ulcers related to systemic sclerosis: results from the RAPIDS-2 randomised, double-blind, placebo-controlled trial. Ann Rheum Dis 2011; 70:32-8.

15. Brueckner CS, Becker MO, Kroencke T, Huscher D, Scherer HU, Worm M, et al. Effect of sildenafil on digital ulcers in systemic sclerosis: analysis from a single centre pilot study. Ann Rheum Dis 2010;69:1475-8.

16. Preliminary criteria for the classification of systemic sclerosis (scleroderma). Subcommittee for scleroderma criteria of the American Rheumatism Association Diagnostic and Therapeutic Criteria Committee. Arthritis Rheum 1980;23:581-90.

17. LeRoy EC, Medsger TA Jr. Criteria for the classification of early systemic sclerosis. J Rheumatol 2001;28:1573-6.

18. European Medicines Agency. Tracleer: European Public Assessment Report. Summary of product characteristics. Updated 2011. [Internet. Accessed April 29, 2014.] Available from: www.ema. europa.eu/docs/en_GB/document_library/EPAR_-_Product_ Information/human/000401/WC500041597.pdf

19. Merkel PA, Herlyn K, Martin RW, Anderson JJ, Mayes MD, Bell P, et al. Measuring disease activity and functional status in patients with scleroderma and Raynaud's phenomenon. Arthritis Rheum 2002;46:2410-20.

20. Georges C, Chassany O, Mouthon L, Tiev K, Toledano C, Meyer O, et al. Validation of French version of the Scleroderma Health Assessment Questionnaire (SSc HAQ). Clin Rheumatol 2005; 24:3-10

21. Tugwell P, Bombardier C, Buchanan WW, Goldsmith CH, Grace E, Hanna B. The MACTAR Patient Preference Disability Questionnaire - an individualized functional priority approach for assessing improvement in physical disability in clinical trials in rheumatoid arthritis. J Rheumatol 1987;14:446-51.

22. Leplege A, Ecosse E, Verdier A, Perneger TV. The French SF-36 Health Survey: translation, cultural adaptation and preliminary psychometric evaluation. J Clin Epidemiol 1998;51:1013-23.

23. Denton CP, Krieg T, Guillevin L, Schwierin B, Rosenberg D, Silkey $\mathrm{M}$, et al. Demographic, clinical and antibody characteristics of patients with digital ulcers in systemic sclerosis: data from the DUO Registry. Ann Rheum Dis 2012;71:718-21.

24. Maddali-Bongi S, Del Rosso A, Mouthon L. Hand function in systemic sclerosis. In: EULAR textbook on systemic sclerosis. Hachulla E, ed. London: BMJ; 2013:274-86.

25. Avouac J, Walker U, Tyndall A, Kahan A, Matucci-Cerinic M, Allanore Y, et al. Characteristics of joint involvement and relationships with systemic inflammation in systemic sclerosis: results from the EULAR Scleroderma Trial and Research Group (EUSTAR) database. J Rheumatol 2010;37:1488-501. 